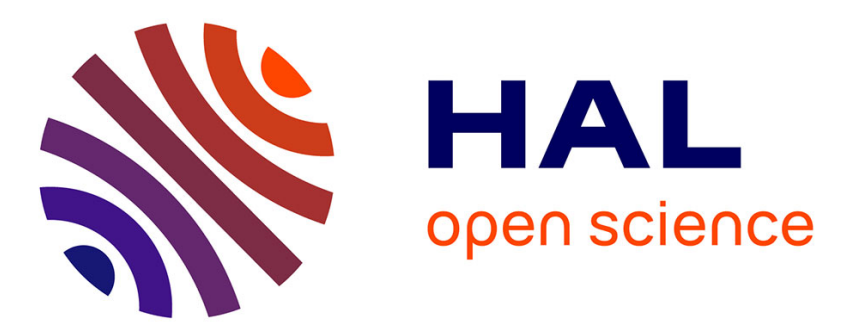

\title{
A monetary measure of the strength and robustness of the attraction effect
}

Paolo Crosetto, Alexia Gaudeul

\section{To cite this version:}

Paolo Crosetto, Alexia Gaudeul. A monetary measure of the strength and robustness of the attraction effect. Economics Letters, 2016, 149 (December), pp.38-43. 10.1016/j.econlet.2016.09.031 . hal01404549

\section{HAL Id: hal-01404549 \\ https://hal.science/hal-01404549}

Submitted on 27 May 2020

HAL is a multi-disciplinary open access archive for the deposit and dissemination of scientific research documents, whether they are published or not. The documents may come from teaching and research institutions in France or abroad, or from public or private research centers.
L'archive ouverte pluridisciplinaire HAL, est destinée au dépôt et à la diffusion de documents scientifiques de niveau recherche, publiés ou non, émanant des établissements d'enseignement et de recherche français ou étrangers, des laboratoires publics ou privés. 


\title{
A Monetary Measure of the Strength and Robustness of the Attraction Effect ${ }^{\text {th }}$
}

\author{
Paolo Crosetto $^{\mathrm{a}}$, Alexia Gaudeul ${ }^{\mathrm{b}}$ \\ ${ }^{a}$ GAEL, INRA and Univ. Grenoble Alpes, 38000 Grenoble, France \\ ${ }^{b}$ Georg-August-Universität Göttingen, Göttingen, Germany
}

\begin{abstract}
The Attraction Effect has been studied in conditions of indifference among options and measured at the aggregate level. We introduce a new within-subjects design based on induced preferences and psychometrics. Our method yields two individual-level measures: the traditional, frequency measure and a new, monetary indicator. The monetary indicator measures the robustness of the effect to decreases in the relative utility of the target with respect to the competitor. We find choice frequencies consistent with the literature. Our monetary measure shows that subjects still prefer the target up to the point where it is $8 \%$ more expensive than the competitor.
\end{abstract}

JEL Codes: C91, D12, D83

Keywords: Asymmetric Dominance, Attraction Effect, Psychometrics, Induced Preferences, Experimental Economics

Contact: paolo.crosetto@grenoble.inra.fr (Paolo Crosetto), a.gaudeul@gmail.com (Alexia Gaudeul) 


\section{Introduction}

The Attraction or Asymmetric Dominance effect (ADE) is a violation of a basic axiom of decision theory, whereby choice is Independent of Irrelevant Alternatives. The ADE was first documented by Huber, Payne, and Puto (1982). Consumers who are subject to the ADE are more likely to choose a target product rather than its competitor if the target is presented along with a decoy product that is clearly dominated by the target, than if it is presented against the competitor only.

The ADE has been widely replicated in consumer research (Huber and Puto, 1983; Simonson, 1989; Park and Kim, 2005; Malkoc, Hedgcock, and Hoeffler, 2013), experimental economics (Herne, 1999; Sonsino, 2010; Kroll and Vogt, 2012), cognitive psychology (Trueblood et al., 2013), and even in biology, in studies of birds (Schuck-Paim, Pompilio, and Kacelnik, 2004) and bees (Shafir, Waite, and Smith, 2002). The ADE "may be one of the biggest exports from marketing research to other fields" (Huber, Payne, and Puto, 2014).

The robustness of the ADE has recently been put into question (Frederick, Lee, and Baskin, 2014; Yang and Lynn, 2014; Huber, Payne, and Puto, 2014; Simonson, 2014). One clear limitation of the ADE literature is that it has studied only situations in which the decision maker is close to indifference between the alternatives proposed. In the words of Huber, Payne, and Puto (2014),

[t]o the extent that a decision maker has clear preferences between the target and the competitor, the effect of adding an undesired decoy will be muted. [...] However, when prior preferences are weak, stemming either from unfamiliarity or indifference, [...] context will matter.

It is no surprise then that most of the literature relies on hypothetical choices, ${ }^{1}$ meaning that money-oriented subjects are indifferent across options. Even the few incentivized experiments (Herne, 1999; Doyle et al., 1999; Lichters et al., 2015) study situations in which subjects should be indifferent between target and competitor.

The ADE literature shows that preferences are context-dependent: choices can be influenced by careful engineering of the choice set. However, this has only been shown in contexts of indifference - when any external cue might affect choice, and the effect matters the least. As Frederick, Lee, and Baskin (2014) puts it, "the boundary conditions for the effect seem to be so restrictive that its practical validity should be questioned.".

Virtually all studies on asymmetric dominance rely on a between-subjects experimental design. Choices from a set with two options, target and competitor, which vary in two unrelated dimensions (e.g., quality and price) but sit on the same indifference curve, are compared with choices from the same set but with an added decoy, an option that is strictly dominated by the target in one dimension (Figure 1, left). The ADE is measured as the difference in choice frequency of the target across those two sets.

In this paper we introduce an experimental method to explore the strength of the attraction effect when options differ in utility. We let the competitor sit not only on the same but also on higher or lower indifference curves compared to the target (Figure 1, right). By varying within subjects the induced value of the target, our design allows us to evaluate the monetary cost of being subject to the ADE.

Compared with the traditional design, which offers only an aggregate frequency measure, our method provides an individual measure expressed in monetary terms. This is a step beyond proofof-concept studies and towards real-world applicability.

\footnotetext{
${ }^{1}$ Out of 52 studies listed in Lichters, Sarstedt, and Vogt (2015) only one uses an incentive-compatible design.
} 


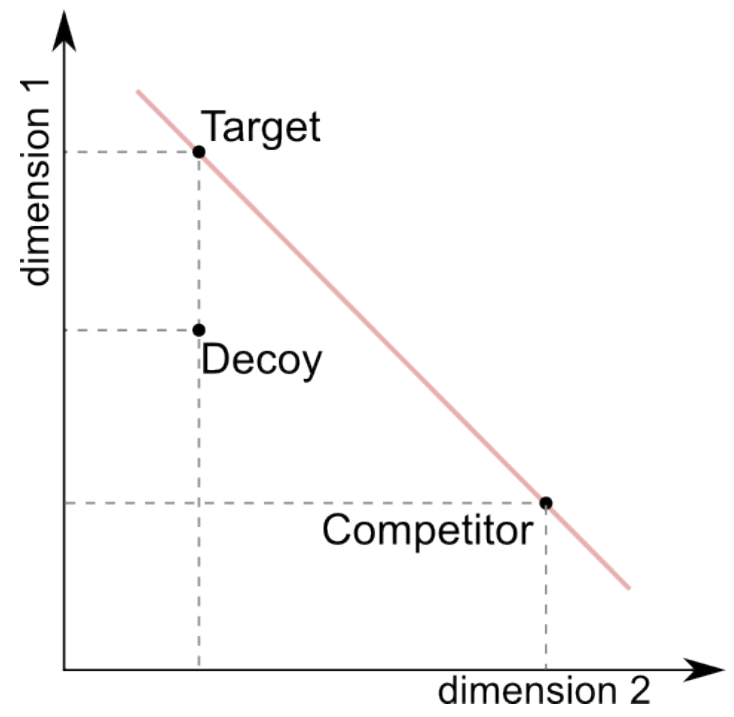

(a) Standard design: indifference

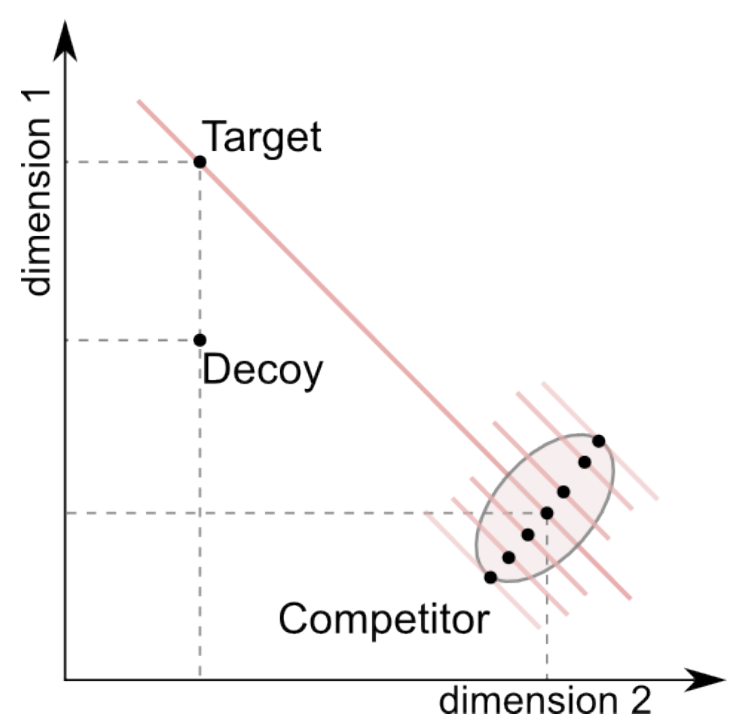

(b) Our design: varying preference for competitor

Figure 1: Experimental Design of ADE experiments: standard vs. our design

\section{Materials and methods}

In the $\mathrm{ADE}$ literature, the options in a choice set usually vary along two not readily comparable dimensions: quality $v s$ price or size $v s$ location for apartments (see the list in Frederick, Lee, and Baskin, 2014, appendix A). In a recent paper Trueblood et al. (2013) employ an unincentivized visual perception task in order to test if the ADE can be considered a fundamental trait of human perception. Subjects must repeatedly indicate the largest of three rectangles, target, competitor and decoy. Target and competitor have the same area, but different length/width ratios. The ADE results are replicated.

We implement a visual perception task similar to Trueblood et al. (2013), but crucially adding incentives. Subjects are asked to imagine to have to buy paint in order to cover a fixed, square area. They face three options: target, competitor and decoy. Subjects are not given unit prices (price/ $\mathrm{m}^{2}$ painted) but rather a price per bucket. Buckets differ in terms of the surface they can cover, which is shown to subjects.

The task is conceptually simple but perceptually difficult. To find the best deal, subjects must compare prices and surface areas across options. Subjects are incentivized to minimize expenditure: they are given an endowment to buy a fixed amount of (fictitious) paint, and earn the money they have not spent. Subjects repeat the task several times, with different shapes, sizes and prices.

Our design replicates most features of the standard ADE task while at the same time introducing an objective standard to evaluate outcomes - unit prices. Relying on induced preferences allows us to manipulate the relative utility of the target with respect to the competitor.

\subsection{Task details}

Subjects faced 18 different choice tasks. Within and across tasks we varied the shape and size of the options, and the relative utility of the target with respect to the competitor.

Shapes could be circles, squares, or equilateral triangles (Krider, Raghubir, and Krishna, 2001).

Size normalizing the total area to be painted to $100 \mathrm{~m}^{2}$, size took one of 12 possible values ranging from $10 \mathrm{~m}^{2}$ to $43 \mathrm{~m}^{2}$, in steps of $3 \mathrm{~m}^{2}$, yielding small but still noticeable size differences.

Unit prices (price per $\mathrm{m}^{2}$ ) were randomly drawn, half from $\sim N(0.5,0.01$ ), half from $\sim N(0.5,0.05)$. No price was allowed to be so high as to result in a potential loss for the subject. 
The options were displayed as a gray shape centered on a white background representing the total area to be painted. The decoy was introduced as an option with the same shape and size as the target but with a higher price (Figure 2).

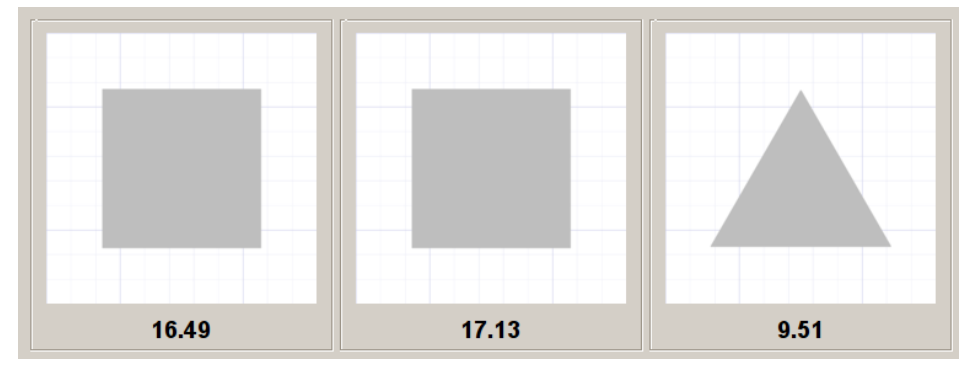

Figure 2: A task. The decoy is the central square, identical but more expensive than the left one.

As a result of the random draw of unit prices, the utility premium of the target varied across tasks (Figure 3), from a situation in which the competitor yielded $9.6 €$ more than the target $(41 \%$ more) to an opposite situation in which it yielded $9.5 €$ less $(-83 \%)$.

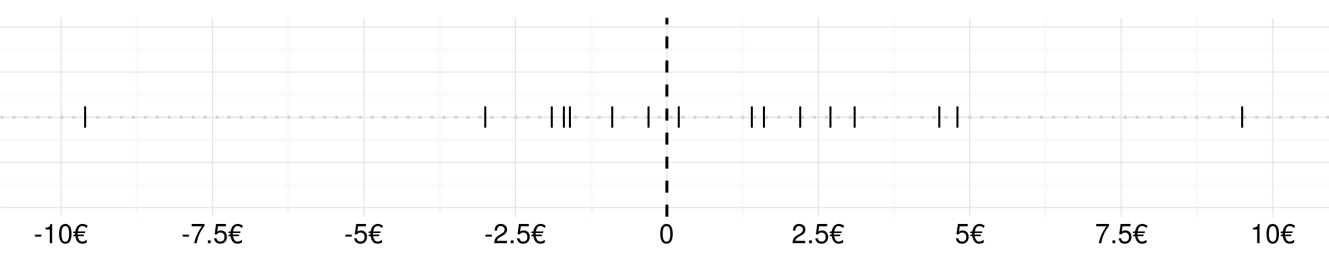

Figure 3: Absolute profit premium of the target w.r.t. the competitor across tasks

Subjects were exposed to the tasks ${ }^{2}$ in random order, had up to two minutes per task and were forced to spend a minimum of 10 seconds on each.

Subjects received feedback after completing each task. Feedback included the total cost of the chosen option and the payoff but no information on unit prices or the cost of other options. At the end of the experiment, one randomly selected task was paid in cash.

\subsection{Experimental details}

202 student subjects took partin June 2011 to the experiment at the laboratory of the Max Planck Institute in Jena, Germany. ${ }^{3}$ Payoffs averaged $11.44 €$ for an experiment lasting between 45 and 75 minutes. $^{4}$

\subsection{Measures}

We analyze the data by means of psychometric measures, as recently done in economics by Lunn and Somerville (2015). A psychometric function (Wichmann and Hill, 2001; Klein, 2001) is a parametrically estimated sigmoid function that relates the subject response to an independently varying stimulus. ${ }^{5}$ In our data, the response is the choice of the target, and the stimulus is its utility premium w.r.t. the competitor. For a rational, perfectly discriminating subject the function would cross the 50\% probability of choosing the target at the point where the utility difference is zero, and would have a steep slope in that neighborhood (Figure 4, left).

\footnotetext{
${ }^{2}$ Visually represented in Online Appendix C.

${ }^{3}$ Data presented in this paper are a subset of a wider investigation. For the analysis of the full dataset see Crosetto and Gaudeul (2011).

${ }^{4}$ Instructions are available in online appendix A.

${ }^{5}$ Psychometric functions are similar to Fechner errors, widely used in experimental economics. For an example see online appendix B.
} 


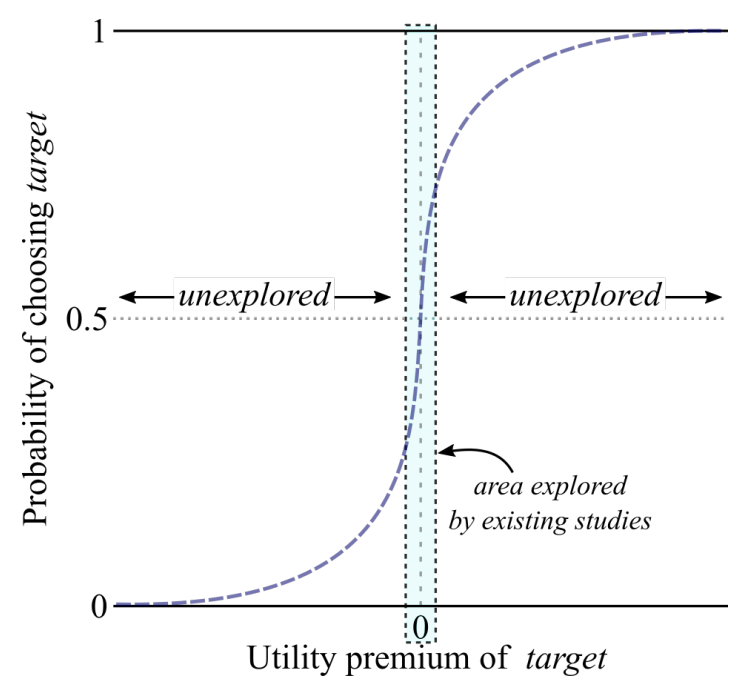

(a) Homo œeconomicus $\left(\beta_{0}=0, \gamma_{0}=4\right)$

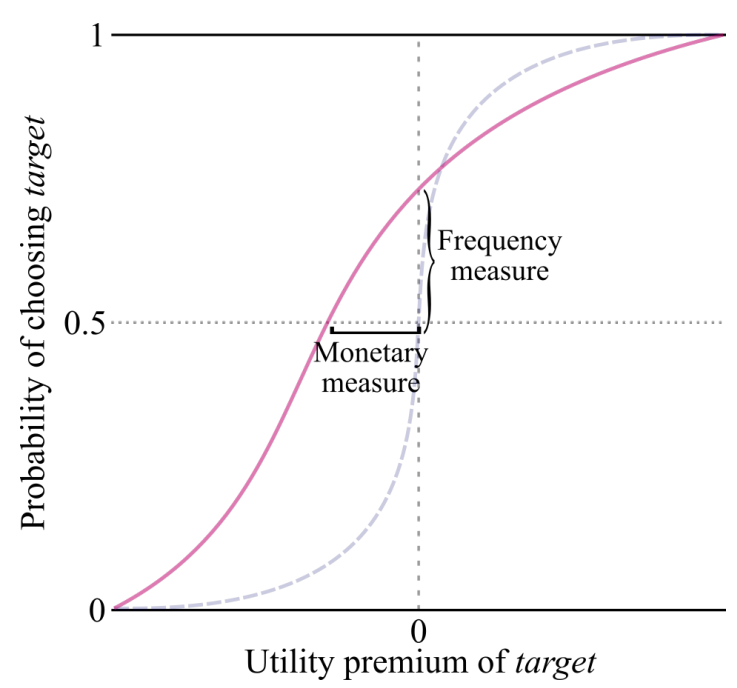

(b) $\operatorname{ADE}\left(\beta_{0}=1, \gamma_{0}=0.6\right)$

Figure 4: Psychometric function and ADE measures

If a subject can only imprecisely discriminate among the options, the slope of the function in the neighborhood of the zero-difference point is lower. The flatter the slope, the lower the precision of the decision maker. If asymmetric dominance has an effect, then the function crosses the zerodifference point at a probability higher than $50 \%$ (Figure 4, right).

The vertical distance on the zero-difference line between the estimated function and the $50 \%$ probability line is the traditional - frequency - measure of the ADE. At the individual level, this represents the likelihood of choosing the target when it gives the same utility as the competitor. At the aggregate level, this is the share of subjects choosing the target.

The horizontal distance on the 50\%-probability line between the estimated function and the zero-difference line is our monetary ADE measure. It represents the money lost due to the attraction effect. A positive monetary measure means that the subject is leaving money on the table by choosing the asymmetrically dominant option.

We estimate parameters in a mixed-effect logit model (1) in which the dependent variable is the choice of the target ( 1 if target, 0 if competitor or decoy). We allow both the constant and the slope of the function to vary across subjects indexed by $i$ :

$$
\ln \left[\frac{\operatorname{Pr}\left(y_{i}=\text { target }\right)}{1-\operatorname{Pr}\left(y_{i}=\right.\text { target }}\right]=\left(\beta_{0}+u_{i}\right)+\left(\gamma_{0}+v_{i}\right) \times \text { premium } .
$$

Premium is the \% utility premium of the target, $\beta_{0}$ and $\gamma_{0}$ are fixed effects coefficients describing the average effect in the population, and $u_{i}$ and $v_{i}$ are the random effects. Given this structure, the frequency $\mathrm{ADE}$ measure is computed, at the individual level, at the point of zero utility premium:

$$
\text { Frequency-ADE } \mathrm{A}_{i}=\frac{1}{1+e^{-\left(\beta_{0}+u_{i}\right)}}
$$

while the monetary ADE measure is computed at the point where $\operatorname{Pr}\left(y_{i}=\right.$ target $)=50 \%$, thus giving the ratio

$$
\text { Monetary- } \mathrm{ADE}_{i}=-\frac{\beta_{0}+u_{i}}{\gamma_{0}+v_{i}} .
$$

The monetary measure depends on both the intercept and the slope of the estimated function: it can take different values for the same measured frequency-ADE, depending on the attitude of the subject towards dominance and his choice precision. 


\section{Results}

Over all 18 tasks, irrespective of utility premium, the target is chosen $56.7 \%$, the competitor $37.4 \%$ and the decoy $5.8 \%$ of the time. As expected, these shares vary according to the premium. Table 1 reports the estimation results for the full dataset (1) and excluding choices of the decoy (2). The full model includes all choices but imposes a stronger requirement for ADE, since it still fixes the bar at 50\%, rather than comparing with the choice share of the competitor. The restricted model correctly imposes $50 \%$, but at the price of disregarding all dominated choices. ${ }^{6}$

\begin{tabular}{lcc}
\hline \multicolumn{2}{c}{ Choice of target } \\
& (1: all choices) & $(2:$ drop dominated $)$ \\
\hline Fixed effects parameters \\
Constant & $0.164^{* * *}$ & $0.308^{* * *}$ \\
\multicolumn{4}{c}{$(0.045)$} & $(0.044)$ \\
Tpremium & $0.020^{* * *}$ & $0.021^{* * *}$ \\
\multicolumn{4}{c}{$(0.002)$} & $(0.002)$ \\
Random effects parameters & \\
Var $\left(u_{i}\right)$ & 0.380 & 0.339 \\
Var $\left(v_{i}\right)$ & 0.004 & 0.002 \\
\hline Observations & 3,423 & 3,423 \\
Log Likelihood & $-2,372.068$ & $-2,195.247$ \\
\hline Note: ${ }^{*} \mathrm{p}<0.1 ;{ }^{* *} \mathrm{p}<0.05 ;{ }^{* * *} \mathrm{p}<0.01$ & \\
\multicolumn{4}{c}{ Table $1:$ Mixed-effect Logit results }
\end{tabular}

Figure 5 plots the estimated psychometric function (center), on average (blue line) and for each subject (gray lines), and the distributions of the monetary (top) and frequency (right) measures across individuals for model (1). The average frequency-ADE is $53.9 \%$ (different from $50 \%$, t-test $p<0.001$ ). This means that even when target and competitor yield equal payoffs, the target is chosen significantly more than half of the time. The average monetary-ADE is $8.02 \%$ (different from zero, t-test $p<0.001$ ). The target is still chosen more than $50 \%$ of the time up to the point where it is $8.02 \%$ more expensive than the competitor. Subjects are incurring losses with respect to optimal behavior because of their preference for the asymmetrically dominant offer: subjects are losing on average 90 cents out of 11.4 Euro per choice. $76.2 \%$ of subjects are affected by the ADE.

When dropping choices of the decoy, results are stronger (Figure 6). The frequency-ADE increases to $57.9 \%$ and the monetary-ADE to $14.9 \%$ (both significant $p<0.001$ ), meaning that subjects are losing on average 1.7 out of 11.4 Euro per choice. $94 \%$ of subjects are affected by ADE.

\section{Conclusion}

We showed in this paper how to exploit induced preferences to measure the size of the attraction effect when moving away from the situations of indifference between target and competitor that are assumed in the existing literature. By employing psychometric measures in a within-subjects task, we estimated at the individual level a new monetary measure of the ADE.

A vast majority of participants are subject to an attraction effect and pay a price for it. The average subject is more likely to choose the target up to when it is $8 \%$ less profitable than the competitor ( $14.9 \%$ if we exclude decoy choices).

${ }^{6}$ For both models the random effects are normally distributed: Shapiro-Wilk test p-value $=0.681$ (1) and $0.948(2)$ 

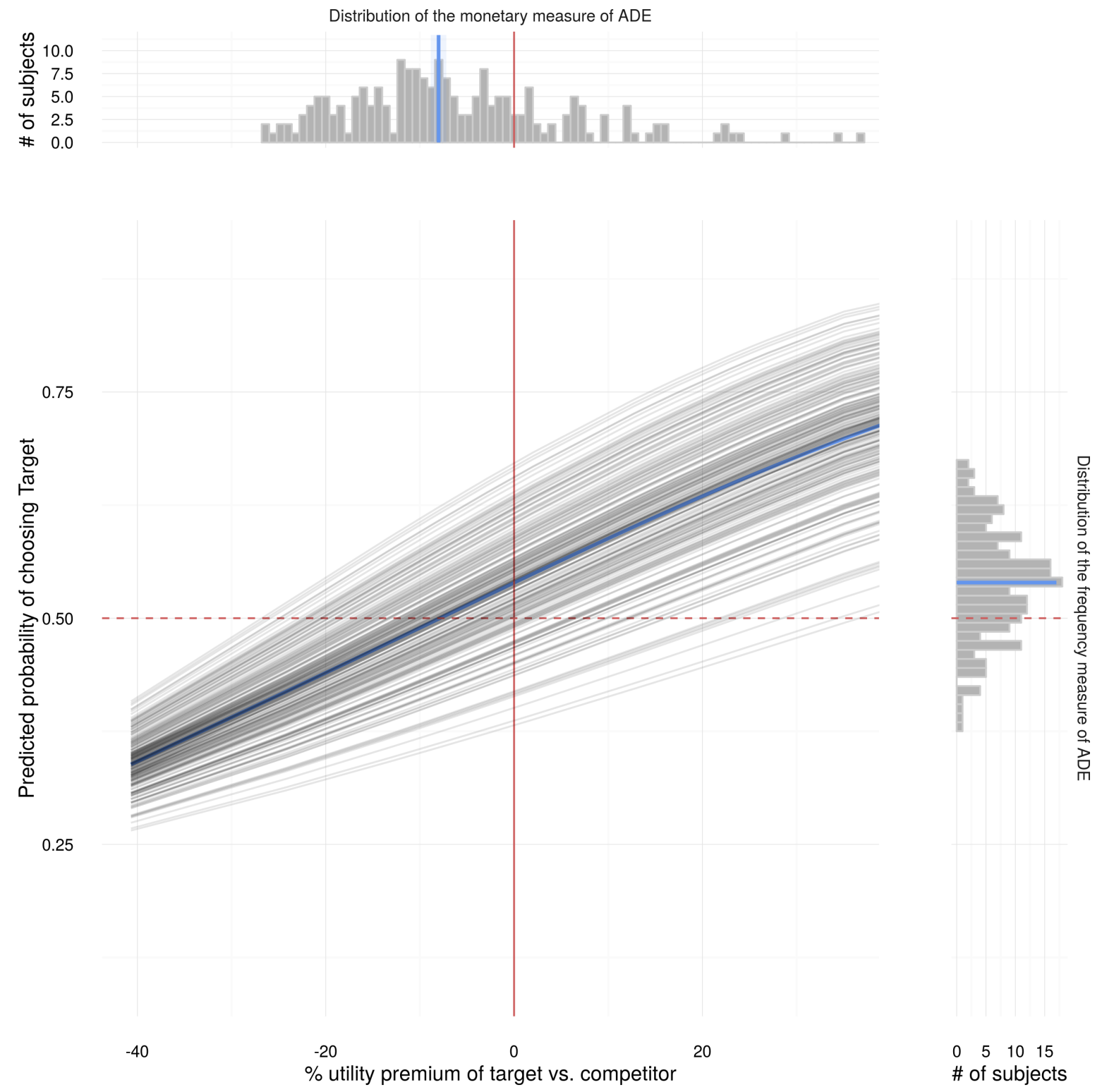

Figure 5: Individual estimated psychometric functions and ADE measures - all data 

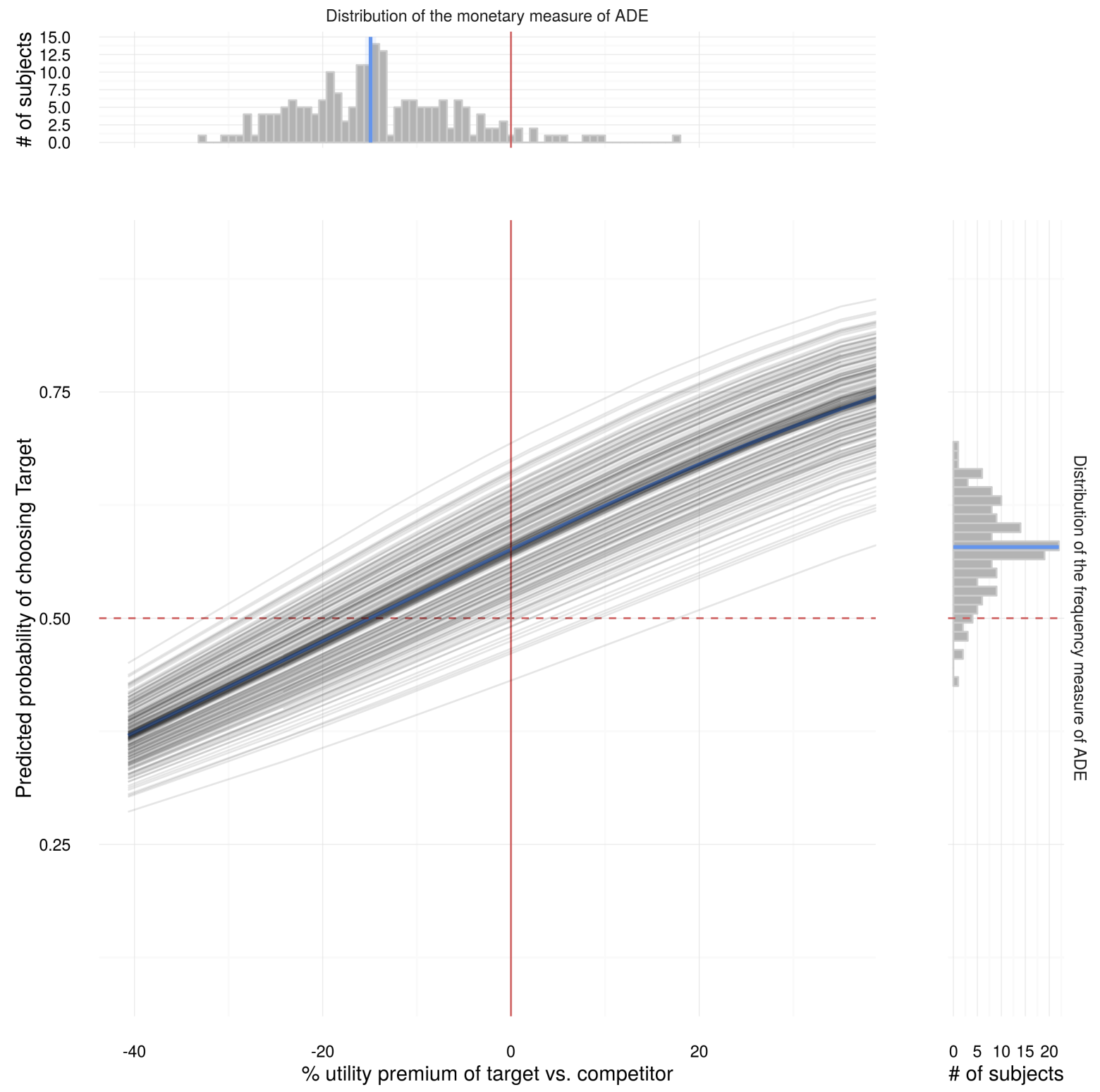

Figure 6: Individual estimated psychometric functions and ADE measures - no decoy 
The value of the monetary-ADE depends on the nature of the stimuli used - here, comparing the size of shapes. Future research will show how this measure varies with different stimuli and how it generalizes to real market conditions.

\section{Acknowledgements}

The research presented in this paper was financed by the Max Planck Institute of Economics, Jena, Germany. 


\section{References}

Crosetto, P., and A. Gaudeul. 2011. "Do consumers prefer offers that are easy to compare? An experimental investigation.” Jena Economic Research Papers No. 2011-044, Friedrich-Schiller-University Jena, Oct.

Doyle, J.R., D.J. O'Connor, G.M. Reynolds, and P.A. Bottomley. 1999. "The robustness of the asymmetrically dominated effect: Buying frames, phantom alternatives, and in-store purchases." Psychology and Marketing 16:225-243.

Frederick, S., L. Lee, and E. Baskin. 2014. “The Limits of Attraction.” Journal of Marketing Research 51:487507.

Herne, K. 1999. “The Effects of Decoy Gambles on Individual Choice.” Experimental Economics 2:31-40.

Huber, J., J.W. Payne, and C. Puto. 1982. "Adding Asymmetrically Dominated Alternatives: Violations of Regularity and the Similarity Hypothesis." Journal of Consumer Research 9:90-98.

Huber, J., J.W. Payne, and C.P. Puto. 2014. “Let's Be Honest About the Attraction Effect.” Journal of Marketing Research 51:520-525.

Huber, J., and C. Puto. 1983. "Market Boundaries and Product Choice: Illustrating Attraction and Substitution Effects." Journal of Consumer Research 10:31-41.

Klein, S.A. 2001. "Measuring, estimating, and understanding the psychometric function: A commentary." Perception \& Psychophysics 63:1421-1455.

Krider, R.E., P. Raghubir, and A. Krishna. 2001. "Pizzas: $\pi$ or Square? Psychophysical biases in area comparisons." Marketing Science 20:405-425.

Kroll, E.B., and B. Vogt. 2012. "The relevance of irrelevant alternatives.” Economics Letters 115:435 - 437.

Lichters, M., P. Bengart, M. Sarstedt, and B. Vogt. 2015. "What really matters in attraction effect research: when choices have economic consequences." Marketing Letters, pp. 1-12.

Lichters, M., M. Sarstedt, and B. Vogt. 2015. "On the practical relevance of the attraction effect: A cautionary note and guidelines for context effect experiments.” AMS Review 5:1-19.

Lunn, P., and J.J. Somerville. 2015. "Surplus Identification with Non-Linear Returns.” Papers No. WP522, Economic and Social Research Institute (ESRI).

Malkoc, S.A., W. Hedgcock, and S. Hoeffler. 2013. "Between a rock and a hard place: The failure of the attraction effect among unattractive alternatives.” Journal of Consumer Psychology 23:317-329.

Park, J., and J. Kim. 2005. "The Effects of Decoys on Preference Shifts: The Role of Attractiveness and Providing Justification.” Journal of Consumer Psychology 15:94-107.

Schuck-Paim, C., L. Pompilio, and A. Kacelnik. 2004. "State-Dependent Decisions Cause Apparent Violations of Rationality in Animal Choice.” PLoS Biol 2:2305-2315.

Shafir, S., T.A. Waite, and B.H. Smith. 2002. "Context-dependent violations of rational choice in honeybees (Apis mellifera) and gray jays (Perisoreus canadensis).” Behavioral Ecology and Sociobiology 51:180-187.

Simonson, I. 1989. "Choice Based on Reasons: The Case of Attraction and Compromise Effects." Journal of Consumer Research 16:158-174.

—. 2014. "Vices and Virtues of Misguided Replications: The Case of Asymmetric Dominance." Journal of Marketing Research 51:514-519.

Sonsino, D. 2010. “The irrelevant-menu affect on valuation.” Experimental Economics 13:309-333.

Trueblood, J.S., S.D. Brown, A. Heathcote, and J.R. Busemeyer. 2013. "Not just for consumers context effects are fundamental to decision making." Psychological science 24:901-908.

Wichmann, F.A., and N.J. Hill. 2001. "The psychometric function: I. Fitting, sampling, and goodness of fit." Perception \& psychophysics 63:1293-1313.

Yang, S., and M. Lynn. 2014. "More Evidence Challenging the Robustness and Usefulness of the Attraction Effect." Journal of Marketing Research 51:508-513. 


\section{A. Online appendix: Experimental Instructions}

Plese note: the instructions reported here refer to the full experiment, that included also choices among 6 options. This paper analyzes only the 18 tasks with 3 options that featured a decoy option.

Welcome to this experiment!

\section{General rules / proceedings}

During the experiment you are not allowed to talk to other participants. Please switch off your mobile phone. If you have any questions, please raise your hand and refer directly to the experimenters. One of the experimenters will then answer your question in private.

Please read these instructions carefully, as your payment will depend on the decisions that you make during this experiment.

On your desk you will find this instruction sheet, a pen, paper, and a receipt. You can take notes at any time; the receipt will only be used for your personal payment at the end of this experiment. During the experiment, we will not speak of Euro but use ECU (Experimental Currency Units) as a currency instead.

The amount of ECU you earn during the experiment will be converted into Euro at the end of the experiment using the following conversion rate: $€ \mathbf{0 . 8}=\mathbf{1}$ ECU. For example, if your earnings amount to $12 \mathrm{ECU}$, you will receive $€ 9.60$. The final payment will be rounded up to the nearest 10 cents.

All participants will remain anonymous, i.e. after the experiment, no one -neither other participants nor the experimenters - will be able to associate your personal information with your decisions or your earnings.

\section{The Experiment}

This experiment consists of several tasks. At the beginning of each task, you are endowed with 60 ECU to buy grey paint from a shop in order to paint a specific, given area. Each shop gives a choice between various offers. Each of them is structured in the same way, i.e. it consists of a given shape and its corresponding price. In each offer, the grey shape on display represents the fraction of the total area (which needs to be painted) that you can paint with this specific offer.

Figure 1 presents the three different offers you are given by a shop. Figure 2 shows the six different offers made by another shop. The total area which you have to paint is represented by the white square surrounding each of the shapes. The light grid is provided to help you with your task.

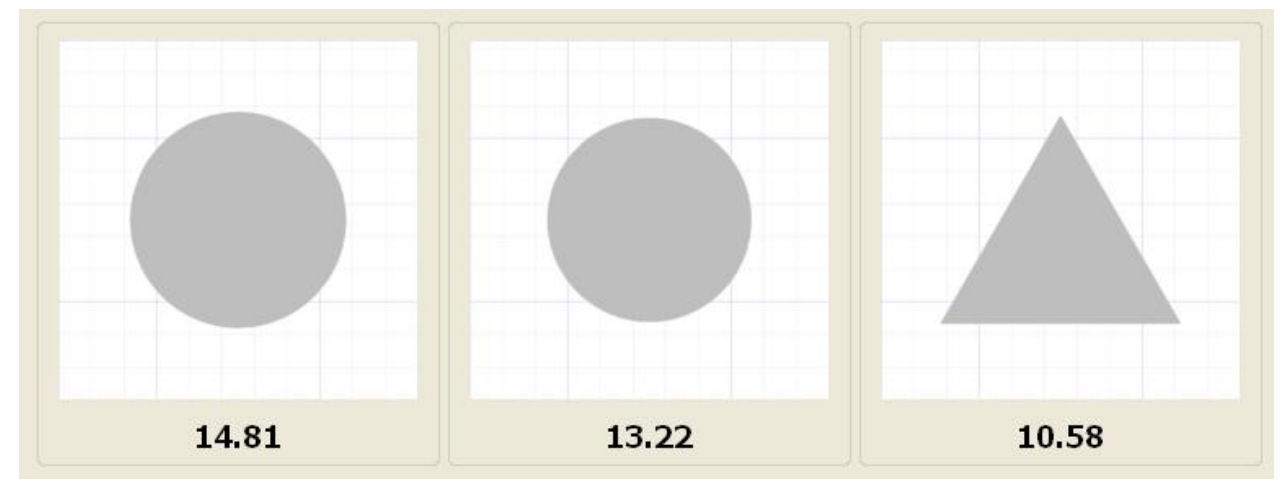

Figure 1

Once you have chosen one of the offers and submitted your choice, the computer will calculate how much paint you need to cover the entire area (the white square) and will also buy the colour for you. The amount of your initial endowment that you do not spend for buying the paint is yours to keep. 


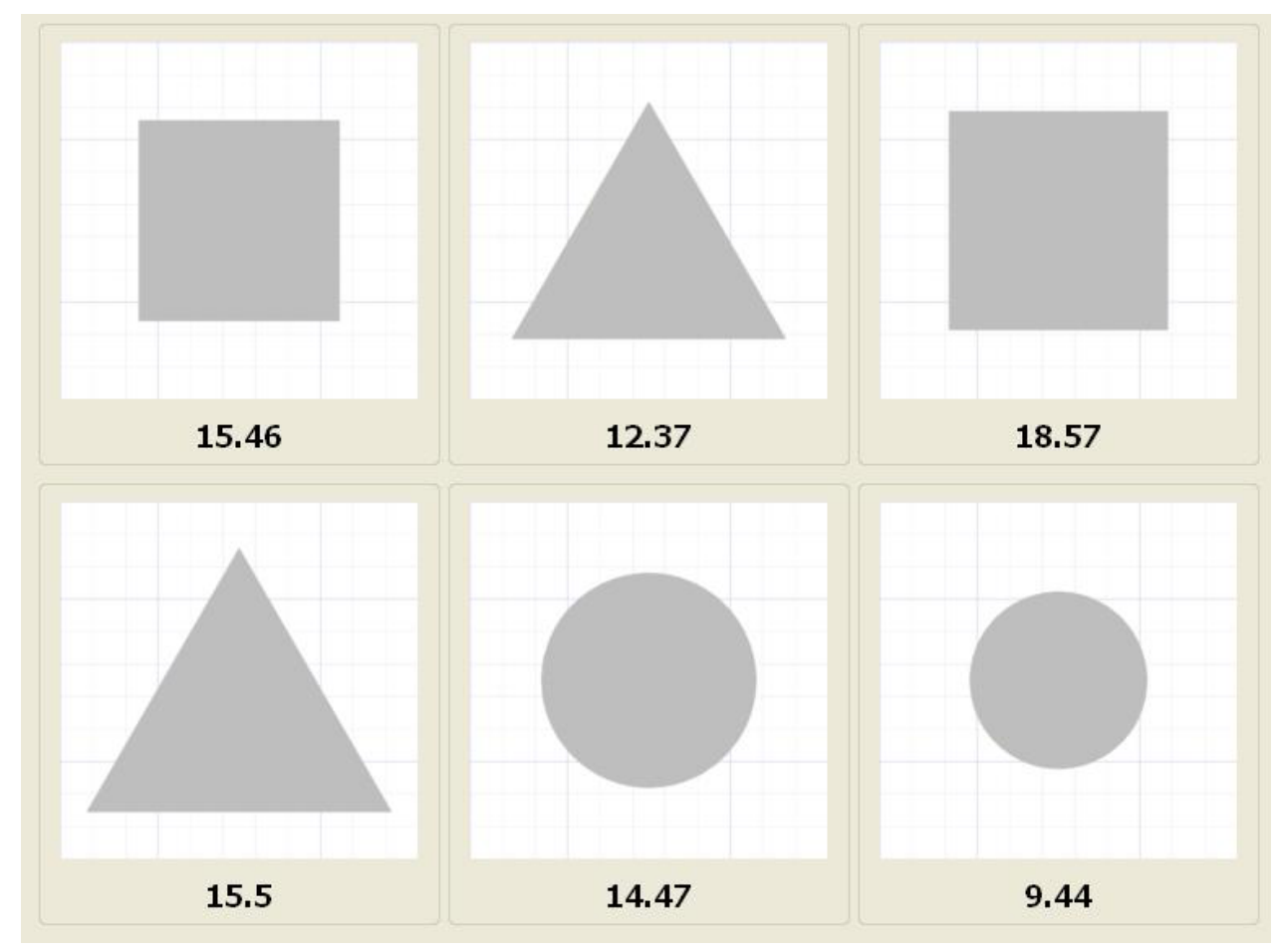

Figure 2

\section{Examples}

The following examples should help you understand how the computations made by the computer work in detail. Suppose you are confronted with the offers in Figure 3 and the total area you are supposed to paint is $100 \mathrm{~m}^{2}$.

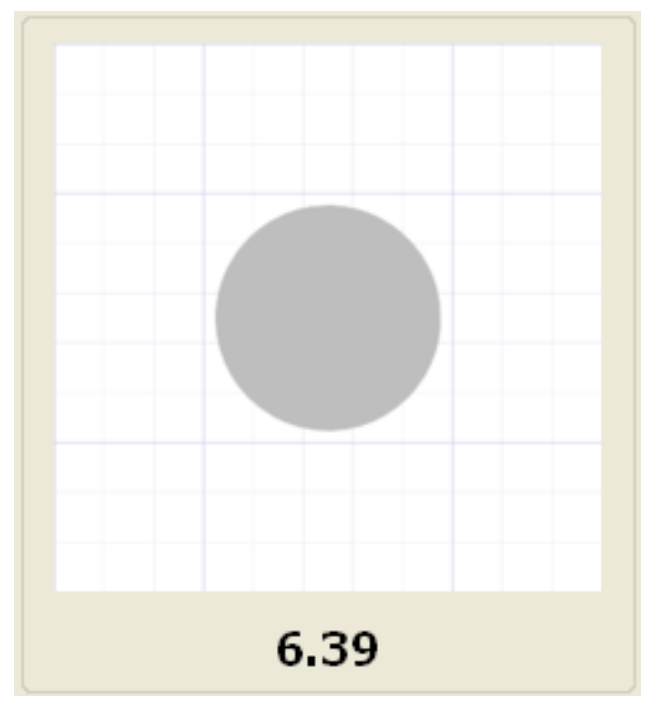

Figure 3

In order to paint the area covered by the grey circle, you pay $6.39 \mathrm{ECU}$.

However, this circle only covers an area of $13 \mathrm{~m}^{2}$. As you need to paint a square which is $100 \mathrm{~m}^{2}$ in size, the computer calculates how much paint you actually need for this offer.

In this case, this amounts to $\mathbf{1 0 0 / 1 3}=\mathbf{7 . 7}$ paint buckets.

Hence, the total price you have to pay for painting the white square amounts to:

$$
6.39 \times 7.7=49.2 \mathrm{ECU}
$$

Keeping in mind your initial endowment of 60 ECU, your earnings result as follows: 


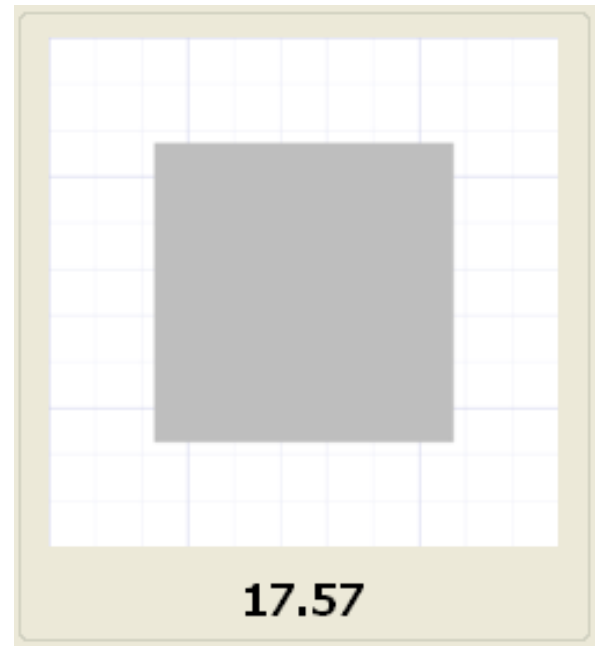

In order to paint the area covered by the grey square, you pay 17.57 ECU.

However, this square only covers an area of $34 \mathrm{~m}^{2}$. As you need to paint a square which is $100 \mathrm{~m}^{2}$ in size, the computer calculates how much paint you actually need for this offer.

In this case, this amounts to $\mathbf{1 0 0 / 3 4}=\mathbf{2 . 9 4}$ paint buckets.

Hence, the total price you have to pay for painting the white square amounts to: $17.57 \times 2.94=\mathbf{5 1 . 7} \mathbf{E C U}$

Keeping in mind your initial endowment of 60 ECU, your earnings result as follows: $60-51.7=8.3 \mathrm{ECU}$

A separate pop-up dialog will automatically appear and will tell you the results of each task (see Figure 4) including your possible earning of this task; clicking 'OK' will start the next task.

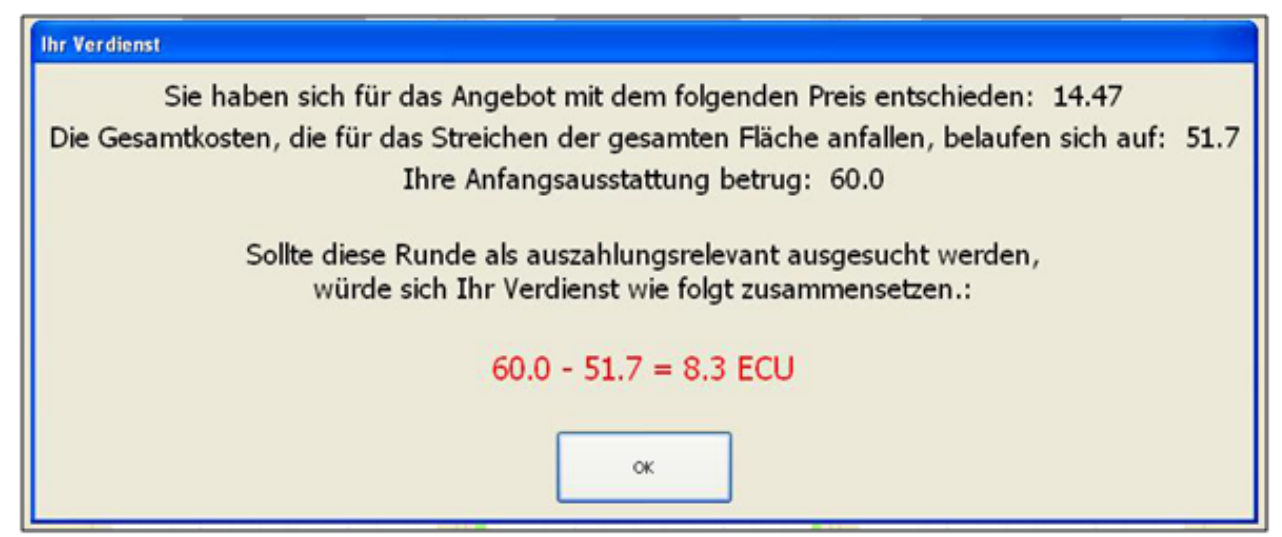

\section{Figure 4}

You have at most two minutes for each task and can only submit a choice at least ten seconds after you started it. In case you made a choice after two minutes (i.e. clicked on one of the offers), but failed to submit the offer in time (by clicking 'OK'), the computer will nevertheless treat your selected offer as if you had submitted it. In case you did not make any choice after two minutes, you will be paid 3 ECU for this task (if this task is chosen as relevant for you payment).

You will be faced with 36 different tasks with 3 offers, and 44 with 6 offers. At the end of the experiment, only one of the 80 tasks will be randomly selected and you will be paid according to your earnings in this specific task.

\section{Questionnaire and Quiz}

Once you completed the 80 tasks, you will be asked to answer a few questions:

1. Please fill in a simple questionnaire. The answers you submit will be treated confidentially and no data will be disclosed. 
2. Please compare different shapes with each other. You have one minute for each of the four comparisons.

3. Please perform some computations. There will be 3 sets of computations and you will have one minute for each.

4. Please solve a number of problems. There will be 4 problems, and you have 2 minutes for each.

After you completed all the tasks, please raise your hand to signal the experimenters that you finished the experiment and we can start with your payment. One of the experiments will then come to your cabin and ask you to draw a chip out of a bag with 80 chips (which are numbered 1 to 80 ). This chip will correspond to the task that you will be paid for. The experiment will then enter the number of the chip on your screen and the computer will automatically tell you, how much you earned in this task. Please fill in this amount as well as your name and signature the receipt that you find on your desk. Afterwards, please raise your hand to signal the experimenters that you are finished filling out your receipt. After you received your payment, the experiment is finished and you can leave the laboratory.

Thank you very much for participating in this experiment! 


\section{B. Online appendix: psychometric function}

The Psychometric Function (PF) is the central analysis tool of psychophysics - the scientific discipline that explores the connection between physical stimuli and subjectiveresponses (Klein, 2001). Typical tasks in psychophysics are detection task - used to identify the thresholds of human perception, for instance using sound or visual stimuli - and discrimination task - used to investigate the way in which two stimuli are compared, for instance when comparing the weight of two objects, or, in economics, the value of two goods Lunn and Somerville (2015).

The $\mathrm{PF}$ is an estimated curve relating the varying stimulus (in abscissa) to a measure of the subject response (in ordinate). An example can make things clear. Consider an experiment in which a single subject is asked to state which of two object of unknown weight, $i$ and $j$, is the heaviest, with no possibility to state indifference. The weight difference between $i$ and $j$ is varied across trials, such that for a single subject judgments are recorded for each level of the weight difference. This is called a two-alternative forced choice (2AFC) design. If we code a correct response as 1 and an incorrect one as 0 , we can build a psychometric function that relates the stimulus (the weight difference, centered on zero) to the probability of a correct response. We expect a subject to make few mistakes when the weight difference is large, and to be more and more confused as the weight difference approaches zero. Given this structure, the function has a sigmoid shape, and can be fitted using logit or probit maximum likelihood estimation (Figure B.7, left).

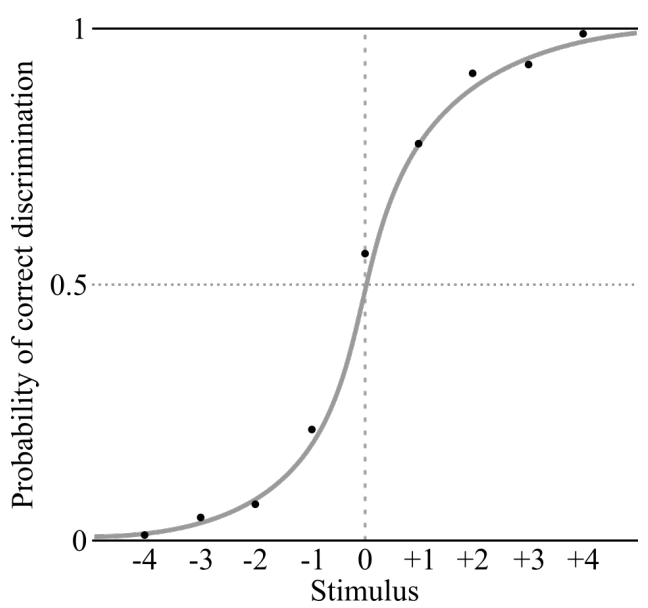

(a) From data to PF

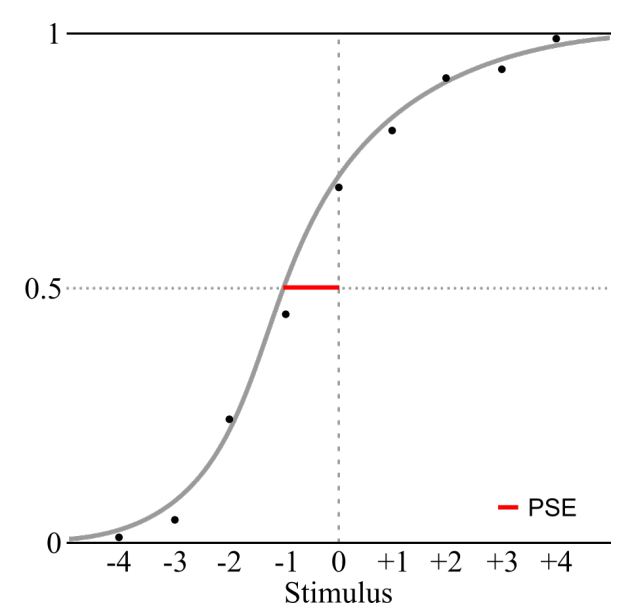

(b) Point of Subjective Equality

Figure B.7: Psychometric Function and related measures

The interest of estimating a $\mathrm{PF}$ is to derive individual measures of the subject response. Of particular interest is the point of subjective equality (PSE) (Figure B.7, right). The PSE is the level of the stimulus for which a subject estimated PF crosses the 50\% probability line. This is the difference in weight between the two objects for which the subject feels they have the same weight. For an unbiased subject, this corresponds to an objective difference of zero; but subjects might have biases. For instance, subjects might judge the bigger object as the heaviest, even when the objective weight of the two objects is the same. Figure B.7, left shows an unbiased subject (PSE $=0$ ), while on the right the subject is biased: she perceives weights as being equal when the objectively measured ones are not.

If the $\mathrm{PF}$ is estimated using logit, then the probability of a correct discrimination is given by

$$
\ln \left[\frac{\operatorname{Pr}\left(y_{i}=\text { correct }\right)}{1-\operatorname{Pr}\left(y_{i}=\right.\text { correct }}\right]=\beta+\gamma \times \text { stimulus. }
$$

The PSE can hence be measured as the point in which the estimated PF crosses the $50 \%$ probability line, i.e. when $\operatorname{Pr}\left(y_{i}=\right.$ correct $)=0.5$. By substituting and solving for stimulus, it can be found that

$$
P S E=\frac{\beta}{\gamma},
$$

i.e., the PSE depends both on the estimated constant and slope of the PF. 
PFs can be fitted to individual subjects, as in this example, or, using the appropriate estimation techniques, to groups of several subjects and conditioning on other observable characteristics of the subject and the task. Detailed guides as to how to correctly estimate PFs are given, among others, by Wichmann and Hill (2001); Klein (2001). For an application to economics, see Lunn and Somerville (2015). 


\section{Online appendix: details of the 18 tasks}

The 18 tasks used in the experiment. The optimal choice in each task - the one minimizing expenditure - is indicated by an asterisk.

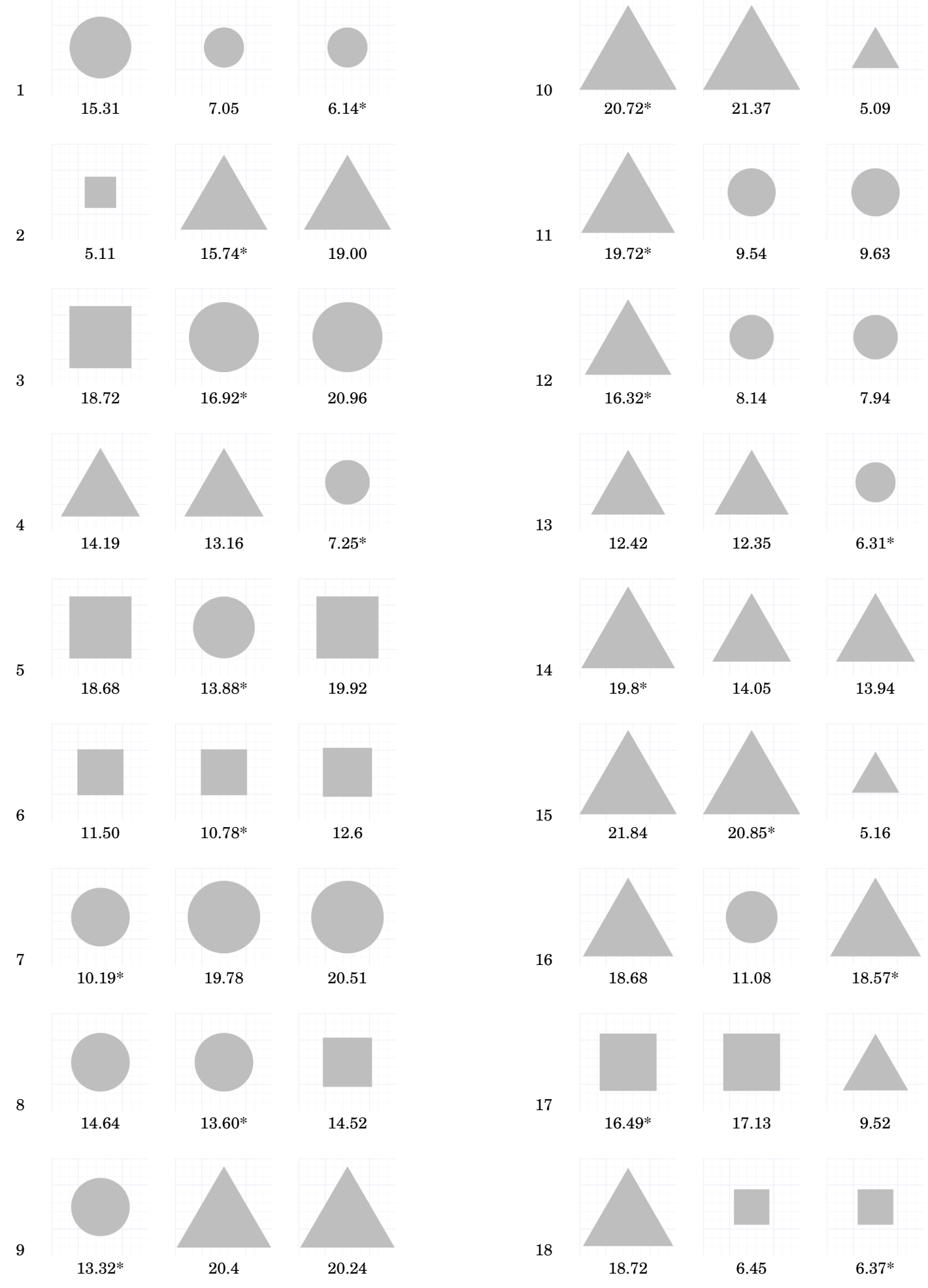

